\title{
COST AND GENERIC PRESCRIPTION ANALYSIS OF PSYCHOTROPIC PRESCRIPTIONS IN PSYCHIATRIC OPD OF A RURAL TERTIARY CARE TEACHING HOSPITAL
}

\author{
Wagle $\mathrm{L}^{1^{*}}$, Kumaraswamy $\mathrm{M}^{2}$; Bajracharya $\mathrm{M}^{3}$ \\ ${ }^{1,3}$ Department of Pharmacy, Manmohan Memorial Institute of Health Sciences, Soalteemode, \\ Kathmandu \\ ${ }^{2}$ Associate Professor, Rajiv Gandhi University, Sri Adichunchanagiri College of Pharmacy, \\ BG Nagara Mandya District, Karnataka India
}

\section{*Corresponding Author:}

Dr.Laxman Wagle, Lecturer, Manmohan Memorial Institute of Health Sciences, Trivuwan University, Kathmandu Email: waglelaxman@gmail.com

\section{ABSTRACT}

Background: There is increased interest on cost utilisation of psychotropic drugs in recent years. Objective of this study was to perform cost and generic prescription analysis of psychotropics in psychiatric outpatient department at tertiary care teaching hospital.

Methods: This was cross sectional, observational and uni-centric study of 6 month duration which was performed at Psychiatric Outpatient Department at one of the tertiary care hospital, Karnataka India. Cost analysis of prescriptions containing at least one psychotropic drug was performed based on cost/defined daily dose method from hospital perspective. Direct drug cost of psychiatric illness per day and pattern of generic prescribing were also studied. The data was analysed \& summarised as mean, frequency, percentage $(\%)$, standard deviation (SD), and chi square test( at 95\% confidence level) as appropriate using Microsoft excel and Graph Pad InStat statistical software.

Results: We observed 15 different types of psychotropics among 101 prescriptions that was reviewed. Most expensive psychotropic was Divalproex whereas Clonazepam was the cheapest one. Most money was spent by hospital on Sertraline $(24.19 \%)$ and least on Lithium (1.92\%). Most expensive therapeutic categories were antidepressants (32.39\%) followed by mood stabilisers (27.06\%), antipsychotics (24.77\%) and sedative/hypnotics (15.76\%). Among different antidepressants; Amitriptyline was cheaper option and Mirtazepine was expensive. Likewise Quetiapine was expensive and Risperidone was cheaper among antipsychotics. Zolpidem and Divalproex were expensive sedative/hypnotic and mood stabilisers respectfully. Most expensive psychiatric illness was found to be bipolar disorder (Rs 20.53 \pm 12.84 ). 19 out of 147 were prescribed with generic names.

Conclusion: The cost burden due to psychiatric drugs is high. Expensive and cheaper psychotropic for psychiatric OPD were Divalproex and Clonazepam respectively. Expensive therapeutic category was found to be antidepressants. From hospital perspective much money was spent on Sertraline and less on Lithium respectively. Similarly high cost of illness was observed in bipolar disorder and less in dissociative disorder. Generic name prescribing is very less.

Key words: Cost analysis of prescription, Cost/DDD, Psychcotropic drugs, 


\section{INTRODUCTION}

The health care system is clearly in state of rapid revolution. Traditional approaches to healthcare decisions where emphasis is basically on clinical outcomes of therapy will no longer suffice; therefore, new tools will be needed which considers the economic and other outcomes of therapy. 1,2 Pharmacoeconomics adopts and applies the principles and methodology of health economics to the field of pharmaceutical policy. Cano and Crane defined Pharmacoeconomics as the economic evaluation of drug therapy, pharmacy program or pharmacy technology. ${ }^{3}$ More appropriately, It can be defined as the branch of economics that uses cost-benefit, cost-effectiveness, cost-minimization, cost-utility analyses to compare pharmaceutical products and treatment strategies. ${ }^{4}$ It makes use of the broad range of techniques used in health economics evaluation to the specific context of medicines management. ${ }^{5}$ Cost analysis study is the simple and effective partial pharmacoeconomic evaluation methods. This type of research in the managed care system is growing especially to make formulary decisions. ${ }^{6}$ In developing country like India where resource may be limited and health care is dominantly provided by private sector ${ }^{7}$; such analysis is more important along with developed countries. ${ }^{8,9}$ where per capital income is much higher. Cost tells about the affordability issues and may relate to non-compliance to treatments. ${ }^{7,10,11}$ Cost effective medicine has to be available in hospital to promote rational use of drugs.

Prescriptions for drugs used for mental disorders are increasing in different parts of the world. ${ }^{12}$ It is note-worthy to see the cost utilisation of psychotropics since phsychiatric illness requires long duration of treatment .Cost of drug vary from time to time and region to region. We performed cost analysis of prescriptions based on cost/defined daily dose (DDD) to see the cost utilisation of each psychotropic drug at the given time horizon. Some Indian studies measured cost data based on average cost / prescription, percentage of cost born by hospital, cost index calculated from different brands etc. ${ }^{13}$ Cost utilisation can also be measured in cost/DDD. Cost/DDD is very useful and convenient method to compare the cost of drugs and also across different therapeutic groups across regions. ${ }^{14}$ It will thus makes easy to see cost burden of each drug and aid in selecting drug in formulary by identifying cheaper and expensive drugs. Generic drug products are often cheaper than branded products. Thus, high cost seen in prescription can be minimised also through generic prescribing ${ }^{15,16}$ This research aimed to assess the cost utilisation of drugs based on cost/defined daily dose to find out expensive and cheaper drugs and their volume of prescribing, to calculate the cost/day of each illness and to assess the pattern of generic prescribing. This research work will throw light on cost burden of psychotropic drugs and their different therapeutic categories, cost burden of different psychiatric illness and status of prescribing in generic name format in psychiatric OPD of tertiary care centre.

\section{MATERIALS AND METHODS}

Study design and type: Cross sectional, observational, semi-quantitative and uni-centric study.

Source of data and materials: Patient prescriptions and data collection form.

Inclusion Criteria: Adults of either sex suffering from psychiatric illness comming to psychiatric outpatient department and patients who had at least one psychotropic medication in prescription. 
Exclusion Criteria: Pregnant and lactating women and patients of epilepsy, parkinsonism and substance use related disorder as well as those cases where diagnoses were not certain.

Ethical clearance: Approved by ethical clearance committee of respective hospital.

Study period : 6 month: October 15, 2014 to April 15, 2015

Study site: Psychiatric Outpatient Department of one of the tertiary care teaching hospital at Karnataka, India.

Sample size: 101 prescriptions

Study Perspective: Hospital perspective

\section{Study procedure and data analysis:}

Data of patients meeting above inclusion and exclusion criteria during study period was collected in custumised data collection form. Following data was collected. patient demographic details, patient diagnosis and prescription details like date of prescription ,out patient prescription number, number of drugs in prescription and their cost. Name of individual drug, its route, dosage form, dosing schedule, duration of therapy and drugs prescribed by generic names.Cost of drugs is calculated from hospital price list in Indian rupees. The data was analysied \& summarised as mean, frequency, percentage (\%), standard deviation (SD), and chi square test /Fischer exact test (at 5\% level of significance) as appropriate using Microsoft excel and Graph Pad InStat statistical software.

\section{RESULTS AND DISCUSSION}

\section{Demographic information of patients}

We had seen that most of the patient population were male, unemployed and within the age group of 31- 40 which was as shown in figure 1, 2 and 3.

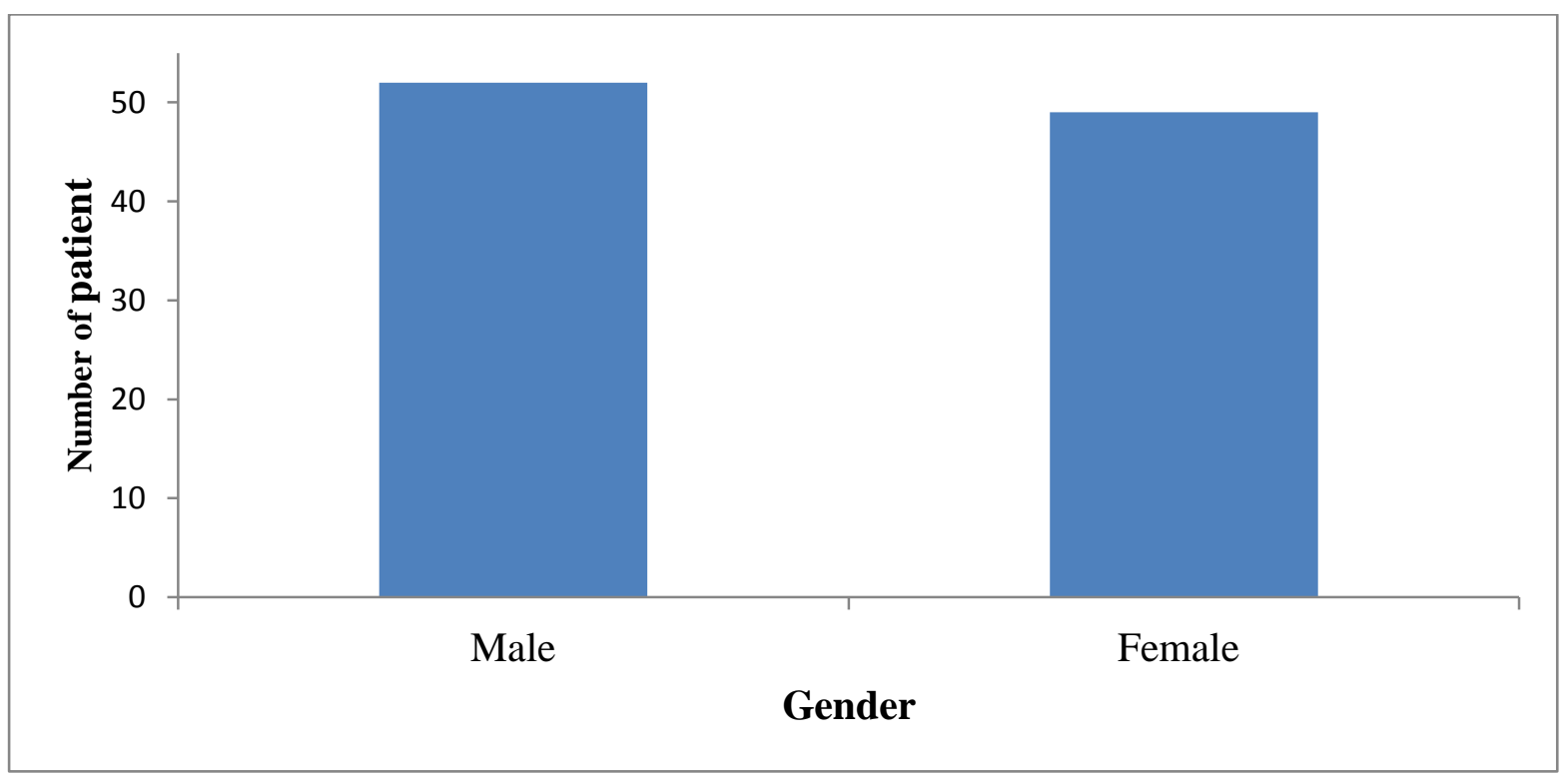

Figure 1: Gender distribution of patients 


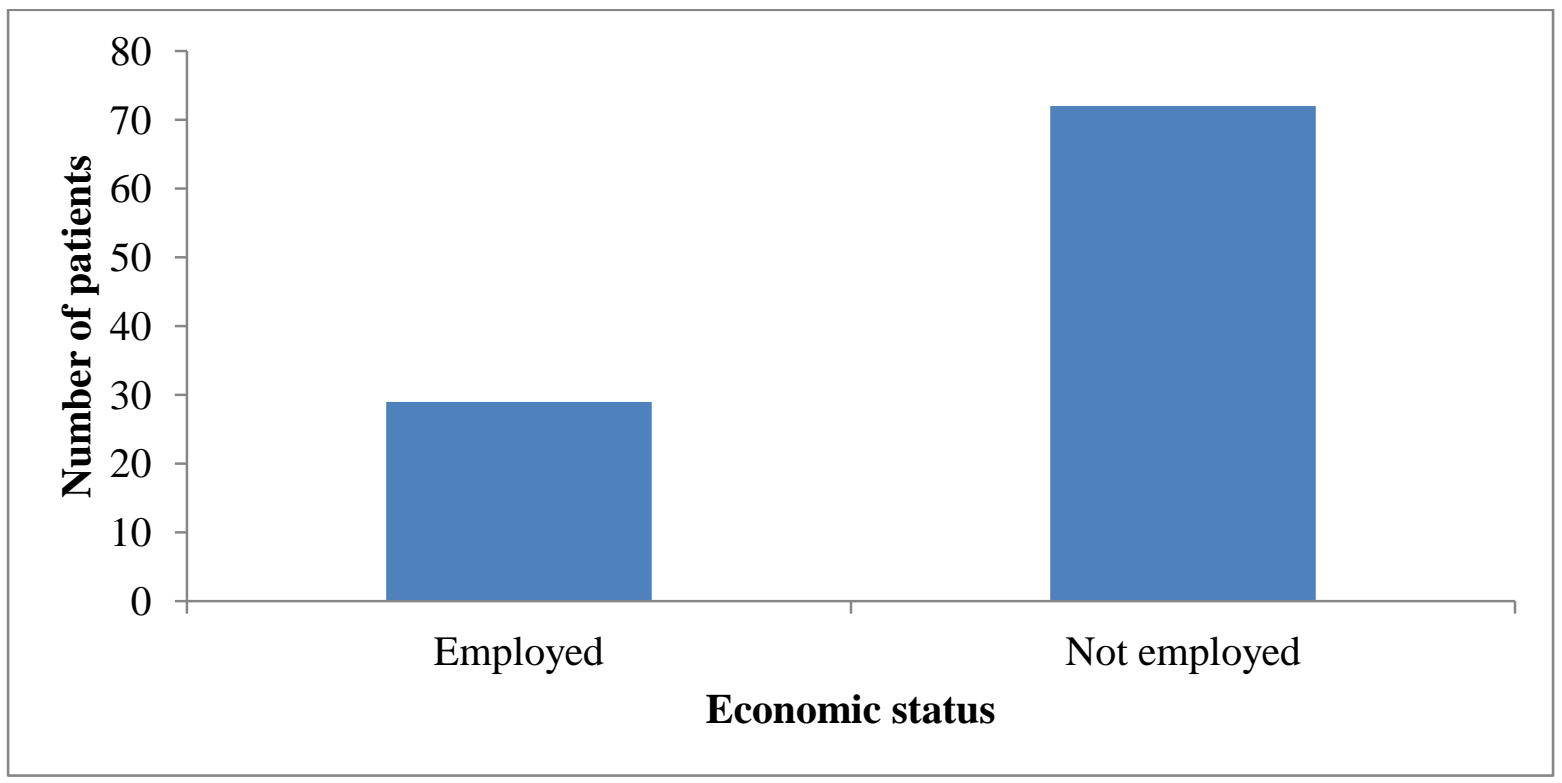

Figure 2: Economic status of patients

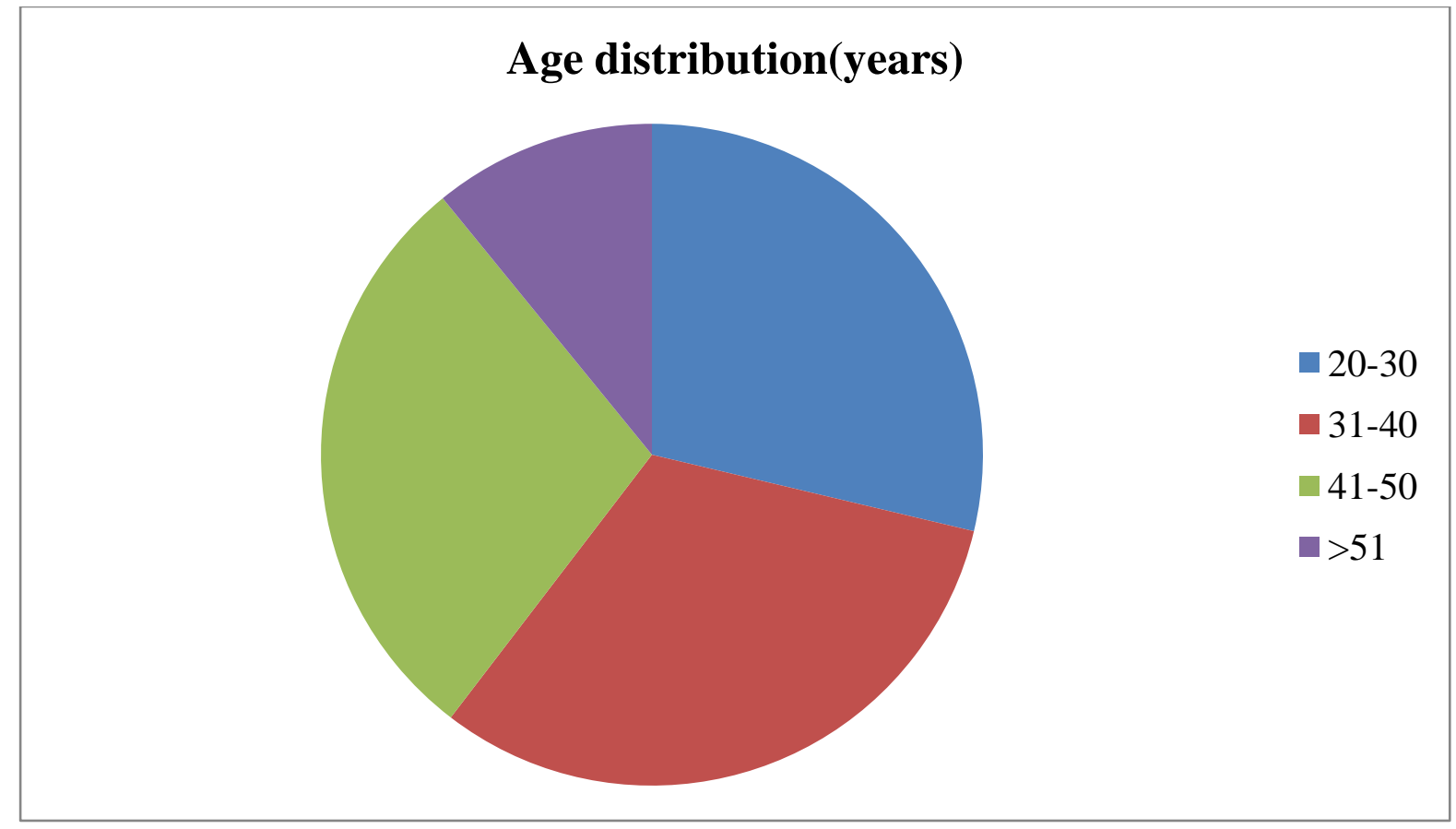

Figure 3: Age distribution of patients

\section{Cost analysis of psychiatric prescriptions}

Understanding the cost of prescription is important for determining compliance and adherence to treatment by patients, especially in mental health disorders where duration of treatment is long, and compliance is known to range from $20-50 \% .{ }^{17}$ Hence, for developing country like India, such study becomes important from different perspective i.e. patient, hospital and society. Our research analyse the prescription from hospital perspective. Based 
on the results we found different cost profile of psychotropic drugs and variation of cost within the same therapeutic class. Most expensive and cheaper therapeutic class, individual drugs, drugs accounting for most hospital expenditure for psychiatry OPD and cost of each psychiatric illness were identified. We observed very less generic name prescribing.

We performed cost analysis of psychotropic drugs based on cost/DDD. WHO developed the DDD as a unit of measurement defined as the assumed average daily maintenance dose of a drug used in its main indication in adults, which however vary for different indications ${ }^{18}$. For the purposes of this study, cost per DDD was defined to mean the cost per average daily maintenance adult dose of a psychotropic drug used in its main indication. Some psychotropics and fixed dose combination do not have assigned DDD but Prescribed daily dose(PDD) can still be calculated using general principles for DDD assignment given by WHO Collaborating Centre for Drug statistic Methodology. Cost/PDD however doesn't allow to compare the particular drug across regions because daily dose may vary. ${ }^{18}$ Table 1 showed the DDD assignment for individual drug which was prescribed during the study period.

Table 1: ATC (Anatomic,Therapeutic,Chemical) classification Code, their DDD, calculated PDD and assessement of DDD/PDD ratio for under or over utilisation of drugs

\begin{tabular}{lllll}
\hline ATC code & Name of drug & PDD $(\mathbf{m g})$ & DDD $(\mathbf{m g})$ & DDD/PDD \\
\hline N05BA12 & Alprazolam & 0.625 & 1 & 1.6 \\
N06AA09 & Amitriptyline & 20.96 & 75 & 3.57 \\
N03AE01 & Clonazepam & 1.244 & 8 & 6.43 \\
& Divalproex & 1000 & & \\
N06AB10 & Escitalopram & 10 & 10 & 1 \\
& Escitalopram & $5+0.5$ & & \\
N05BA19 & plus clonazepam & & & \\
N05AN01 & Etizolam & 0.458 & & 1 \\
N06AX11 & Lithium & $24 \mathrm{mmol}$ & $24 \mathrm{mmol}$ & 1.81 \\
N05AH03 & Mirtazepine & 16.5 & 30 & 1.34 \\
N05AH04 & Olanzapine & 7.43 & 10 & 2.66 \\
N05AX08 & Quetiapine & 150 & 400 & 1.84 \\
N06AB06 & Risperidone & 2.71 & 5 & 53 \\
\hline
\end{tabular}




\begin{tabular}{lllll}
\hline N03AG01 & Valproic acid & 1000 & 1500 & 1.5 \\
N05CF02 & Zolpidem & 8.33 & 10 & 1.20 \\
\hline
\end{tabular}

Note: No any psychotropic drug was over utilised (DDD/PDD $\geq 1$ ) of their dosage in comparision to defined daily dose as recommended by WHO.

According to our results we found that most expensive drug in our psychiatric OPD was Divalproex (Cost/PDD;Rs15.2 \pm 0 ) whereas Clonazepam. (Cost/DDD;2.27 \pm Rs 1.47) was the cheapest psychotropic drug. The profile of cost of other drugs were as shown in table 2 . .Among 15 commonly used psychotropics, most money was spent by hospital on Sertraline (24.19\%) and least on Lithium (1.92\%). Along with Sertraline (24.19\%), Clonazepam (11.63\%), Escitalopram plus Clonazepam, (9.08\%) Risperidone (8.59\%) and Olanzapine $(7.53 \%)$ accounted for $61.04 \%$ of expenditure. Lithium (1.92\%), Zolpidem $(2.54 \%)$, Alprazolam(2.66\%), Etizolam(2.99\%) accounted for just $9.5 \%$ of these expenditure. Most expensive therapeutic categories were antidepressants $(32.39 \%)$ followed by mood stabilisers (27.06\%), antipsychotics (24.77\%) and sedative/hypnotics (15.76\%). Among different antidepressants; Amitriptyline was cheaper option and Mirtazepine was expensive. Likewise Quetiapine was expensive and Risperidone was cheaper among antipsychotics. Typical antipsychotics were not used which is found to be cheaper than atypical ones. ${ }^{7}$ Zolpidem and Divalproex were expensive antianxiety and mood stabilisers respectfully. Weather extra cost/DDD of these drugs is worth or not, has to be evaluated before selecting these drugs for hospital formulary. The drug which are in essential drug list has to be frequently selected. More extensive pharmacoeconomic study can also be carried out further like cost effective or cost utility analysis to see the benefit of drug regimens in individual settings.

Table2: Cost analysis of psychotropic drugs

\section{Class of drugs}

$\begin{array}{lll}\text { No. of times } & \begin{array}{l}\text { Defined } \\ \text { daily }\end{array} & \begin{array}{l}\text { Cost/Defined } \\ \text { daily dose } \\ \text { prescription } \\ \text { dose } \\ \text { (mg) }\end{array}\end{array}$

$\begin{array}{lll}\text { No. of } & \text { Ranking } & \text { Ranking } \\ \text { generic } & \text { for drug } & \text { for cost } \\ \text { Drugs } & \text { cost } & \text { volume }\end{array}$

\section{Anti-psychotics (24)}

Olanzapine

Risperidone

Quetiapine

Anti-depressants(61)

Sertraline

Mirtazepine

Escitalopram

*Escitalopram
8

14

2

29

5

3

plus 11
10

5

400

50

30

10

$* 5+0.5(1 \quad * 5.8 \pm 0$
$6.618 \pm 2.82$

$4.31 \pm 0.37$

$12.6 \pm 9.8$

$5.86 \pm 1.08$

$9.2 \pm 7.49$

$7.6 \pm 0$
1

3

0

2

10 
clonazedpam

Amitriptyline

Mood stabilisers(11)

*Divalproex

Valproic acid

Lithium

Sedatives and hypnotics(51)

Zolpidem

Alprazolam

*Etizolam

Clonazepam
TAB)

13

75

$2.3 \pm 0.64$

2

14

9

Non Psychotropic drugs (40)

Note : For drugs like *Divalproex, *Etizolam and *Escitalopram plus Clonazepam,PDD is calculated instead of DDD to compare cost; according to principle given by WHO Collaborating Centre for Drug statistic Methodology since defined daily dose is not assigned. PDD is calulated from the average daily dose prescribed, as obtained from a representative sample of prescriptions. Ranking of drugs means extent of cost burden in descending order as given by numeral 1,2,3 etc.

We also seen that there was a positive correlation (correlation coefficient; 0.96) between number of drugs in prescription and cost of prescription as shown in table 3.This signifies that increase in cost is linearly related with number of drugs that was prescribed.

Table 3: Drugs per prescription verses cost

\begin{tabular}{lll}
\hline $\begin{array}{l}\text { Number of drugs/prescription } \\
\text { 5drugs/prescription }\end{array}$ & Frequency & $\begin{array}{l}\text { Average Cost }( \pm \text { SD)/day } \\
\text { (Indian rupees) }\end{array}$ \\
4drugs/prescription & 2 & Rs $85 \pm 29$ \\
3drugs/prescription & 2 & Rs $47.29 \pm 22.13$ \\
2drugs/prescription & 8 & Rs $44.64 \pm 13.06$ \\
\hline
\end{tabular}




\section{Note: Correlation coefficient(r) 0.96}

\section{Cost of psychiatric illness}

We had performed cost of illness studies based on direct drug cost as shown in figure 4 .

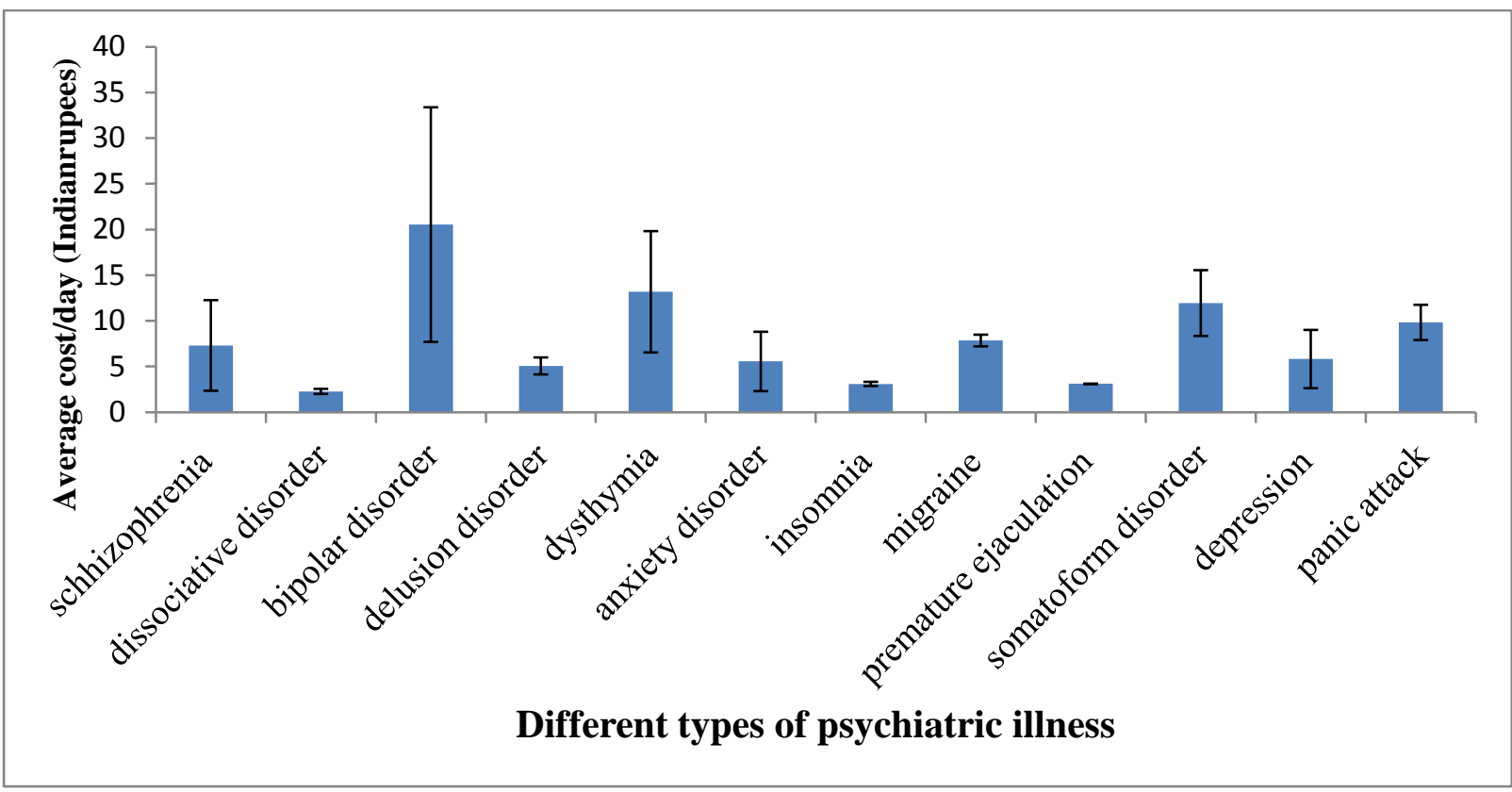

Figure 4: Diagnosis and average direct drug cost/day of psychiatric illness

The cost per day of each psychiatric illness was used to compare cost of different illness. These cost are based on direct drug acquisition cost only. Most expensive psychiatric illness was found to be bipolar disorder (Rs 20.53 \pm 12.84 ) followed by dysthymia (Rs13.17 \pm 6.64 ), somatoform disorder (Rs 11.94 \pm 3.6 ), panic attack (Rs 9.82 \pm 1.93 ) migraine (Rs 7.84 \pm 0.64 ), schizophrenia (Rs 7.34 \pm 4.96 ), depressive disorder (Rs 5.81 \pm 3.19 ) anxiety disorder (Rs $5.55 \pm 3.25$ ), delusion disorder (Rs 5.06 \pm 0.93 ), premature ejaculation (Rs 3.1 \pm 0 ), insomnia (Rs $3.09 \pm 0.23$ ), and dissociative disorder (Rs 2.27 \pm 0.27 ). These all shows that psychiatric medicine can cause high cost burden to the population in our society where majority were not employed.

One way to reduce cost of drugs is to prescribe in generic name format and maintaining formulary in hospital. Our hospital lacks hospital formulary. It is more important to prescribe drugs in generic format because psychotropic drugs available in Indian market is having high variation in cost accounting for more than $100 \%{ }^{7}$ attributed to the factors like poor regulation by drug pricing authorities, hospital still lacks their own formulary, and a part that suboptimal awareness of cost among the doctors etc. ${ }^{18,20}$ Very few drugs i.e. 19 out of 147 were prescribed with generic names. Most frequently Mirtazepine (60\%) and least frequently Clonazepam $(8.33 \%)$ were prescribed with generic names. Similarly for other drugs $\%$ of generic prescribing was Lithium (33.33\%), Sertraline (24.13\%), Risperidone $(21,42 \%)$, Amitriptyline $(15,38 \%)$ and Olanzapine $(12,5 \%)$ as shown in fig: 5. Female, unemployed married and within the age group of 31-40 were more prescribed with generic names as shown in table $5,6,7$. 
Assessment of generic prescribing

Figure 5: Percentage generic prescribing of each drug

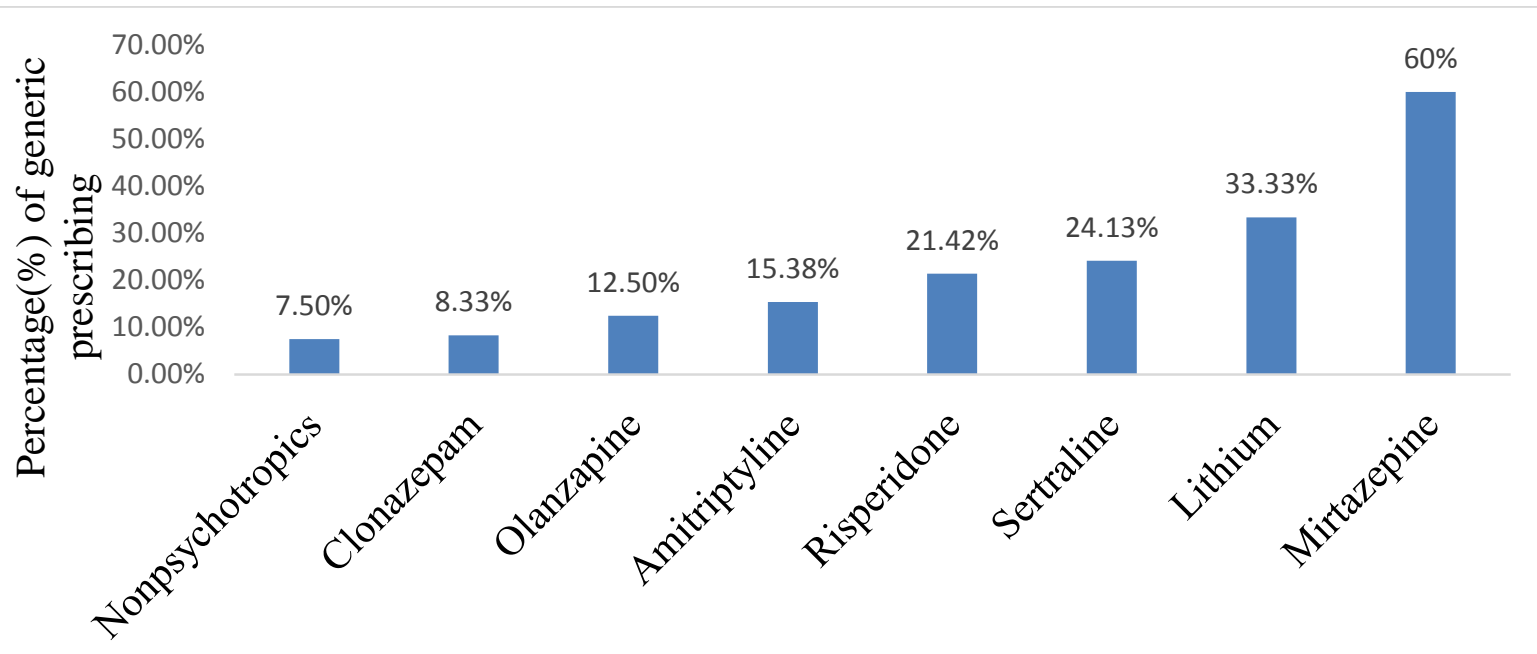

Drugs which were prescribed at least one time with generic name

Table 4: Factors affecting generic prescribing: Gender

\begin{tabular}{|c|c|c|c|}
\hline Sex & $\begin{array}{l}\text { Frequency } \\
\text { prescribing (\%) }\end{array}$ & generic & P Value \\
\hline & Yes & No & \\
\hline Male & 8 & 44 & 0.51 \\
\hline Female & 11 & 38 & \\
\hline
\end{tabular}

Note: $P<0.05$ is statistically significant

Table 5: Factors affecting generic prescribing: Employment status

\begin{tabular}{llll}
\hline Employment status & $\begin{array}{l}\text { Frequency of } \\
\text { prescribing }(\%)\end{array}$ & generic & P value \\
\hline Yes & No & \\
Employed & 7 & 43 & 0.30 \\
Not employed & 12 & 39 & \\
\hline
\end{tabular}

Note: $P<0.05$ is statistically significant

Table 6: Factors affecting generic prescribing: Marital status

\begin{tabular}{lll}
\hline Marital status & $\begin{array}{l}\text { Frequency of generic P value } \\
\text { prescribing }(\%)\end{array}$ \\
\hline
\end{tabular}




\begin{tabular}{llll}
\hline & Yes & No & \\
Married & 17 & 65 & 0.51 \\
Single & 2 & 17 & \\
\hline
\end{tabular}

Note: $P<0.05$ is statistically significant

Table 7: Factors affecting generic prescribing: Age

\begin{tabular}{|c|c|c|c|c|}
\hline Age group & $\begin{array}{l}\text { Frequency } \\
\text { prescribing }(\%)\end{array}$ & of & generic & $P$ value \\
\hline & Yes & No & & \\
\hline $18-30$ & 3 & 26 & & \\
\hline $31-40$ & 11 & 21 & & 0.019 \\
\hline 41-more & 5 & 35 & & \\
\hline
\end{tabular}

Note: $P<0.05$ is statistically significant

Table 8: Generic prescribing trend for psychotropic drugs in India

\begin{tabular}{|c|c|c|c|c|c|c|}
\hline \multirow{2}{*}{$\begin{array}{l}\% \text { of } \\
\text { drugs }\end{array}$} & \multirow{2}{*}{ generic } & $\begin{array}{l}\text { Our } \\
\text { settings }\end{array}$ & Juno $\mathbf{J J}^{23}$ & Odo H. ${ }^{24}$ & $\begin{array}{l}\text { Siddhartha } \\
\text { G }^{22}\end{array}$ & $\begin{array}{l}\text { Thakkar BR } \\
13\end{array}$ \\
\hline & & $12.3 \%$ & $2.36 \%$ & $94.38 \%$ & $92.66 \%$ & $76.01 \%$ \\
\hline
\end{tabular}

This result of generic prescribing is less; compared to other studies in India ${ }^{13,21-24}$ but is welcoming. Generic prescribing trend in India at psychiatric unit was as shown in table 8. There is debate of quality issues where no certainty about bio equivalency in offered generics rendering the prescribers to stick on brands so-that adequate quality control has to be assured. ${ }^{13}$ From hospital perspective, advantages of generic prescribing are to decrease the hospital drug budget. For EU and US healthcare system; outcomes generated by generic drug prescribing is 25 billion pound and $\$ 8.8$ billion savings each year. ${ }^{15,16}$ It is a need to establish own hospital formulary list to address all these issue via development of formulary committee in hospital.

Continuous study is to be needed to see the cost burden over time in our hospital. Our result will not replace formulary selection of psychotropic drugs in other settings. It is also that analysis has to be viewed from direct drug cost only; non-medical cost and direct medical cost other than drug cost, intangible and indirect cost were not included and remained the limitation of this study. Since it is a short period of study some drugs may have still escaped. This research was conducted 3 to 4 years back so the cost of medicine may not reflect today's cost.

\section{CONCLUSION}


The cost burden due to psychiatric drugs is high. Expensive and cheaper psychotropic for psychiatric OPD were Divalproex and Clonazepam respectively. Expensive therapeutic category was found to be antidepressants. From hospital perspective much money was spent on Sertraline and less on Lithium respectively. Similarly high cost of illness was observed in bipolar disorder and less in dissociative disorder. Generic name prescribing is very less. Based on results we would like to recommend that cost analysis auditing will be helpful to understand the cost burden of individual drugs, therapeutic class as a whole and for different illness for hospital as well for patients. Prescribing in generic name format has to be increased.

\section{ACKNOWLEDGEMENT}

We would like to acknowledge all our teachers, seniors and principal of our college and psychiatric OPD to carry out this research work.

\section{REFERENCES}

1. Townsend R H. Post-marketing drug research and development: Drug Intelligence and Clinical Pharmacy. 1987;21:134-136.

2. Kozma CM, Reeder CE, Schulz RM. Economic, clinical, and humanistic outcomes: a planning model for pharmacoeconomic research. Clin Ther. 1993; 15:1121-32

3. Cano SB, Crane VS. Conceptual model for assuring cost effectiveness in hospital pharmacy practice: Glaxo. 1989

4. ArenasGuzman GR, Tosti A, Hay R, Haneke E. JEADV.2005; 19 (1): 34-39.

5. Wally T, Haycox A, Bolond A. Pharmacoeconomics. $1^{\text {st }}$ ed; edition, Churchill Livingstone: $1-14$

6. Purkiss R, Hospital Pharmacist, Pharmacoeconomics - the importance for pharmacist .DICP. 2006; 13:34.

7. Tondare BS, Bhave AK. Cost Analysis of Oral Antipsychotic Drugs Available in the Indian Market. Int. J. Pharm. Sci. Rev. Res. 2015;29(2):267-270

8. Mayer H. Payers to use protocols to assess treatment plans: American Medical News 1998;1:41-44

9. Froemming SH, Cold JA, Wells BG. Pharmacoeconomic evaluations in medicine.. Ann Phramacother. 1989;23:431

10. Shankar R, Palain S. Ambiguous pricing of topical dermatological products: A survey of brands from two South Asian countries. Journal of Pakistan Association of Dermatologists. 2006; 16:134-140.

11. Lallan HN, Borde MK, Ray IM, Deshmukh YA. Cost variation study of antidiabetics: Indian scenario. Indian J Appl Res. 2014;4(5):420-421.

12. Olfson M, Marcus SC. National patterns in antidepressant medication treatment: Arch Gen Psychiatry. 2009; 66:848-856.

13. Thakkar BR. Karan, Jain MM, Mangal G B, Joshi A, Khobragade. A Drug Utilization Study of Psychotropic Drugs Prescribed in the Psychiatry Outpatient Department of a Tertiary Care Hospital. JCDR. 2013;7 (12): 2759-2764.

14. Charles CE., Vincent NU, Ogbonna B. The Utilization Pattern and Costs Analysis of Psychotropic Drugs at a Neuropsychiatric Hospital in Nigeria: British Journal of Pharmaceutical Research. 2014; 4(3): 325-337, 
15. Haas JS, Phillips KA, Gerstenberger EP, Seger AC. Potential savings from substituting generic drugs for brand-name drugs: medical expenditure panel survey 1997-2000. Ann Intern Med. 2005;142: 891-897.

16. European Generic Medicines Association. How to increase patient access to generic medicines in European Healthcare system: 2009,

17. Olivier MR. Psychological factors, compliance and resistance to antidepressant treatment: Encephale. 1986;12: 197-203.

18. World Health Organisation Introduction to drug Utilisation Research. WHO International Working Group for Drug Statistics Methodology, WHO Collaborating Center for Drugs Statistics Methodology. WHO Collaborating Center for Drug Utilisation Research and Clinical Pharmacological Services; 2003,

19. Lowy DR, Low L, Warner R.S. A survey of physician awareness of drug costs: Am J Edu. 1972; 47:349-355

20. Brody B.L, Stokes J. Use of professional time by internists and general practitioners in group and solo practice: Ann Intern Med.1970; 73:741-749

21. Banerjee I, Roy B, Sathian B, Banerjee I, Chakraborty KP, and Saha A. Socio demographic profile and utilization pattern of antipsychotic drugs among schizophrenic inpatients: a cross sectional study from western region of Nepal. Bio Med Central Psychiatry.2013;13:96

22. Siddhartha G, Bhattacharyya S, Kuma DC. Antipsychotic prescription pattern in a tertiary care teaching care hospital of eastern India: Journal of Drug Delivery \& Therapeutics. 2013; 3(4):38-42

23. Juno JJ, Shastry C, Rao S. Evaluation of antipsychotic drug prescriptions in hospitalized schizophrenic patients: IJPRBS. 2015; 4(1): 353-363

24. Odo H, Sunday OS, Imafidon OA, Peter OP, Bawo OB. Evaluation of the drug utilization pattern at a regional psychiatric hospital in Benin city: Nigeria Archives of Pharmacy Practice. 2013;4(4):154-159 